\title{
Posterior reversible encephalopathy syndrome with lumbar drainage and surgery: coincidence or correlation? A case report
}

\author{
Brent G. Oxford, Nicolas K. Khattar, Shawn W. Adams, Alexandra S. Schaber and Brian J. Williams*
}

\begin{abstract}
Background: Posterior reversible encephalopathy syndrome (PRES) is a rare neurological disorder usually associated with specific medical conditions that cause a disturbance of the CNS homeostasis. It has seldom been reported to be a consequence of an iatrogenic intervention causing intracranial hypotension.

Case presentation: We report the case of an individual 69-year-old male presenting with headache and blurred vision following cerebrospinal fluid (CSF) leak from resection of a sellar mass. The patient developed the condition following removal of the lumbar drain post-operatively. Magnetic Resonance Imaging showed bilateral occipital, parieto-occipital, and cerebellar T2 FLAIR hyper-intensities, suggesting a radiological diagnosis of posterior reversible encephalopathy syndrome (PRES). The patient's symptoms started to improve shortly afterwards and had completely resolved at 3 months follow-up.

Conclusions: The absence of severe hypertension and presence of an intraoperative CSF leak requiring placement of the lumbar drain suggests that decreased CSF volume and associated reactive hyperemia could have a role in the pathophysiology of the disease.
\end{abstract}

Keywords: Posterior reversible encephalopathy syndrome, Lumbar drain, Intracranial hypotension, Sellar mass

\section{Background}

Posterior reversible encephalopathy syndrome (PRES) originally described by Hinchey includes neurological abnormalities and associated characteristic findings on neuroimaging [1]. PRES is most commonly associated with eclampsia although it may occur in infections, autoimmune disease, cancer chemotherapy, transplantation, and hypertension [1-3]. Clinical symptoms range from headache, altered mental status, vision changes including cortical blindness, paresis, seizures, and nausea with severe cases leading to coma and death [1-3]. Computerized Tomography (CT) or Magnetic Resonance Imaging (MRI) typically shows a reversible focal symmetric hemispheric edema involving the watershed zones, often in the parietal and occipital lobes [2, 4-6]. In this report,

\footnotetext{
* Correspondence: brian.williams@ulp.org

Department of Neurological Surgery, University of Louisville School of Medicine, 220 Abraham Flexner Way, 15th Floor, Louisville, KY 40202, USA
}

we present the case of a patient with PRES associated with intracranial hypotension after removal of a lumbar drain.

\section{Case presentation}

Our patient is a 69-year-old Caucasian male with known hypertension, hyperlipidemia, gout and sialolithiasis presenting for endoscopic endonasal resection of a recurrent intra/suprasellar mass with cavernous sinus extension with pathological specimen consistent with Rathke's cleft cyst. Cerebrospinal fluid (CSF) leak occurred intra-operatively requiring placement of a lumbar drain at a rate of $10 \mathrm{cc} / \mathrm{h}$. CSF pressure was not elevated during the initial placement. Drainage continued intermittently at the same rate for $48 \mathrm{~h}$. The drain was then clamped for $24 \mathrm{~h}$ prior to removal on post-operative day three without adverse event. The patient did not complain of any headaches following the surgical intervention but developed a severe

(C) The Author(s). 2019 Open Access This article is distributed under the terms of the Creative Commons Attribution 4.0 International License (http://creativecommons.org/licenses/by/4.0/), which permits unrestricted use, distribution, and 
positional headache associated with nausea, vomiting, and significantly blurred vision. The headaches were worsened upon sitting upright and partially relieved in the recumbent position. The ophthalmological examination demonstrated decreased visual acuity at 20/30 bilaterally. The optic disc retained spontaneous venous pulsations, suggestive of low or normal intracranial pressure.

CT of the head revealed subcortical hypodensities at the posterior tip of the occipital lobes bilaterally. MRI demonstrated patchy areas of T2 and T2 FLAIR hyperintensity in the bilateral posterior occipital lobes as well as the bilateral parieto-occipital junction and posterior cerebellum (Fig. 1).

The patient's systolic blood pressure is charted in Fig. 2. The systolic blood pressure ranged between 101 and $174 \mathrm{mmHg}$ and the diastolic blood pressure ranged between 54 and $120 \mathrm{mmHg}$. The red arrow (Fig. 2) represents a blood pressure of $152 / 80 \mathrm{mmHg}$ and corresponds to the exact timing of the lumbar drain removal. The patient had a history of hypertension and was maintained on his home oral anti-hypertensive medications. The acute variations in his systolic blood pressure were being treated with intravenous anti-hypertensives. No CSF leak was noted post-operatively and supportive therapy was continued. The patient's symptoms improved one day later with his visual acuity normalizing on ophthalmological follow-up examination. He was discharged on post-operative day eight with continued improvement of his symptoms at six months follow-up. MRI follow-up at six months showed complete resolution of the T2 lesions (Fig. 1).

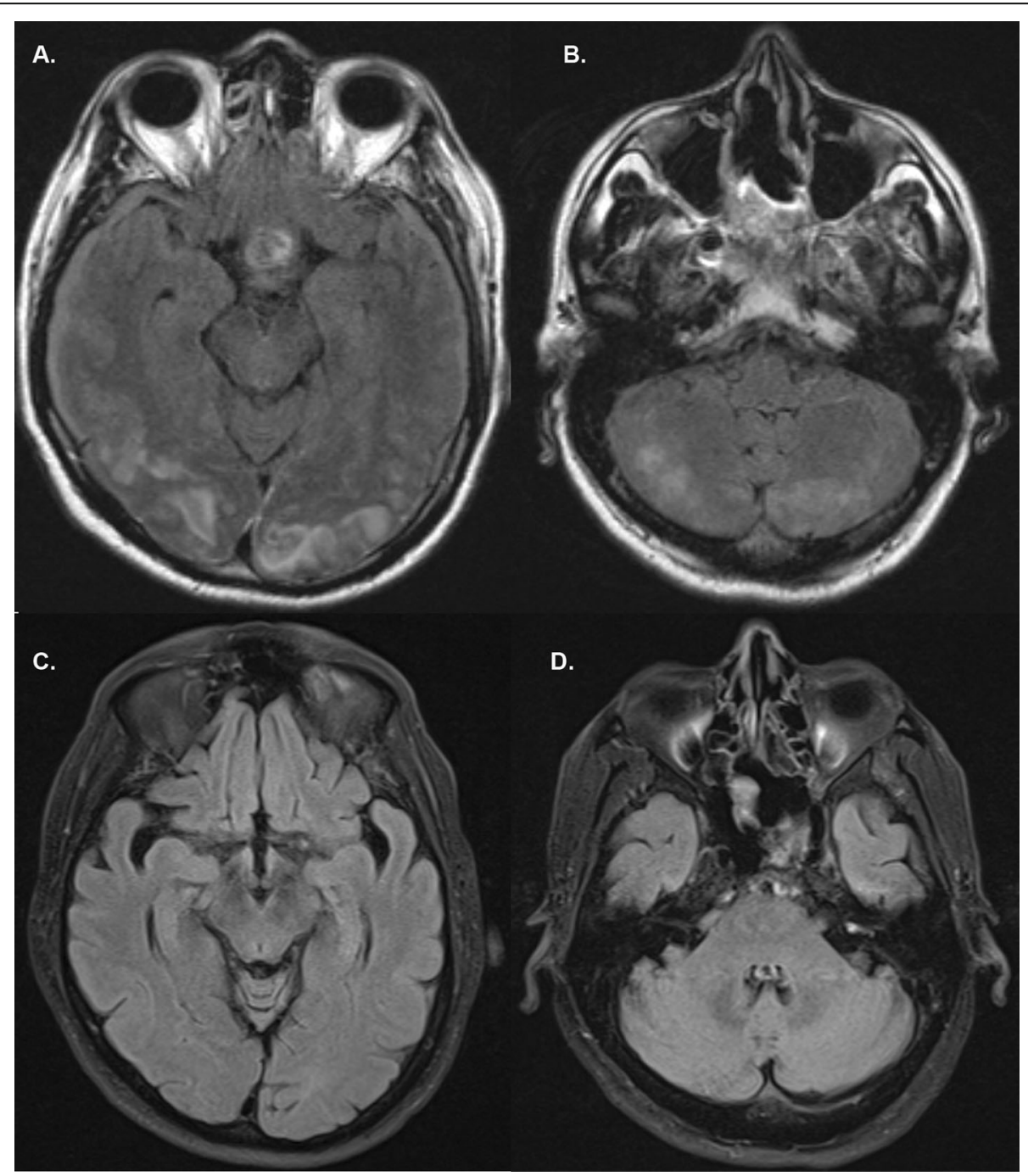

Fig. 1 Axial brain MRI reveals patchy areas of increased T2 FLAIR hyper-intensity in the bilateral occipital lobes (a) and posterior cerebellum (b). Follow-up MRI at 6-months follow-up show complete resolution of the areas of T2 FLAIR hyper-intensity in the bilateral occipital lobes (c) and posterior cerebellum $(\mathbf{d})$ 


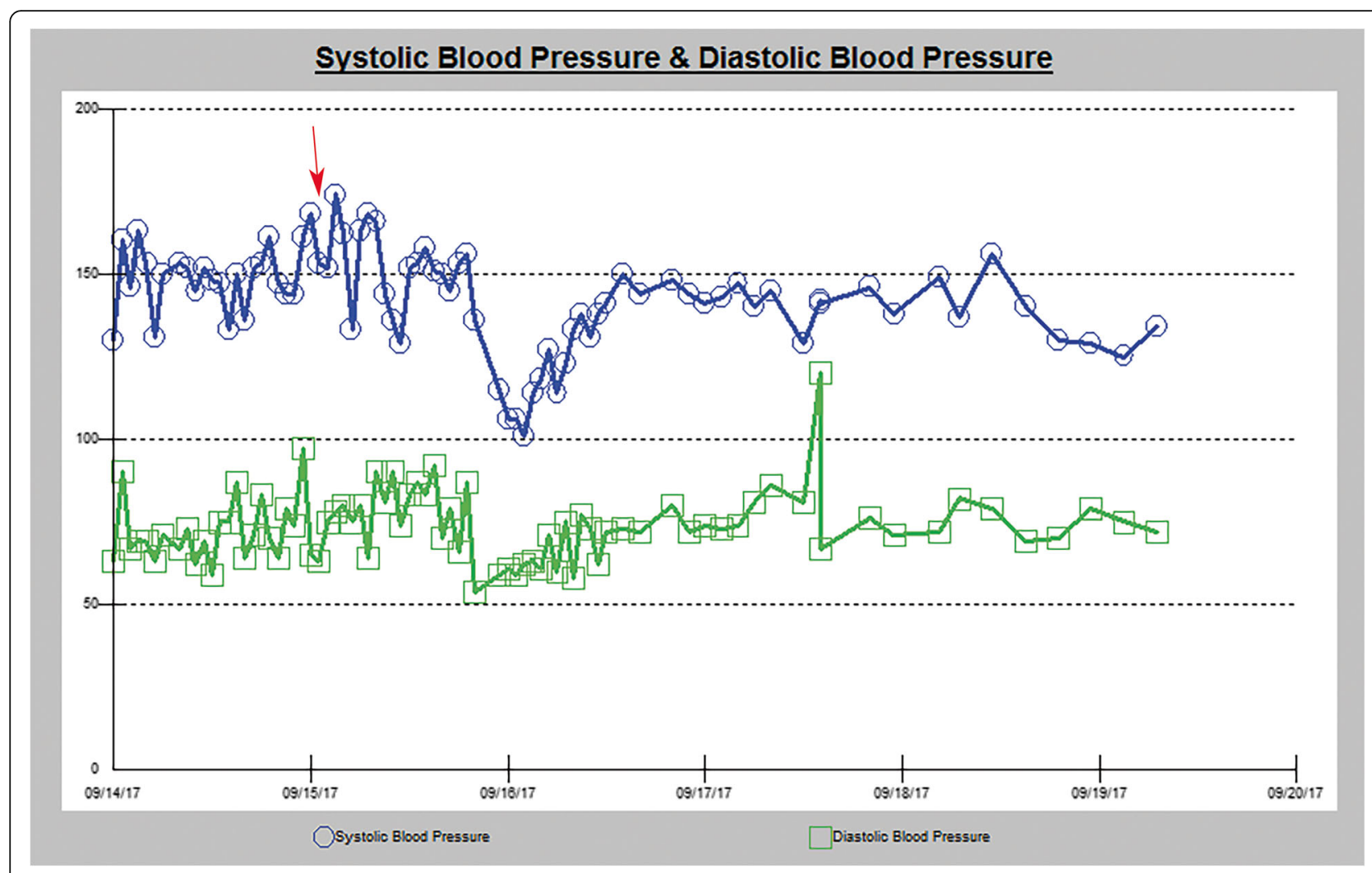

Fig. 2 Systolic and diastolic blood pressure variation during the entire hospitalization. The red arrow depicts the time of the lumbar drain removal

\section{Discussion and conclusion}

Posterior reversible encephalopathy syndrome is a rare disorder, and its mechanism remains controversial. It has been previously described occurring following lumbar CSF drainage [7-10]. One of the prevailing theories suggests that severe hypertension can precipitate cerebral auto-regulatory failure leading to hyperperfusion, endothelial injury and subsequently fluid extravasation [11, 12]. Hypertension may be associated with reflexive vasoconstriction leading to ischemic injury damaging the blood brain barrier and allowing subsequent extravasation [13]. PRES is known to occur in normotensive patients and such a tight association with hypertension is less likely, given that the latter is only present in $70-80 \%$ of cases [4]. In our case, the patient's blood pressure was elevated at $152 / 80$ immediately prior to the removal of the lumbar drain. There could be a potential association of CSF drainage following clamping of the lumbar drain for $24 \mathrm{~h}$ and restoration of normal intrathecal CSF volume, with the instantaneous occurrence of hypertension that led to PRES in that situation. Such CSF drainage would be caused by the presence of a lumbar drain-induced durotomy in the lumbar cistern that would leak additional fluid prior to sealing with compression.

Another potential mechanism of action of PRES involves endothelial dysfunction leading to an increase in membrane permeability and vasogenic edema as seen on imaging $[14,15]$. Even though the mechanism of endothelial dysfunction is mostly unknown, manipulation of areas of cardiovascular regulation such as the hypothalamus (in the setting of a Rathke's cleft cyst resection) could trigger the endothelial dysfunction [16]. This initial insult can trigger an immune response with the release of various cytokines leading to disruption of tight junctions causing vasogenic edema [14]. This inflammatory cascade leading to disruption of vascular endothelium potentially offers an explanation linking the various conditions that have been documented to cause PRES independently of blood pressure abnormalities [2, 14, 15].

Recently, intracranial hypotension has also been associated with PRES [17]. Demonstrating the occurrence of intracranial hypotension is challenging given the absence of ICP measurement in our patient. However, an intraoperative CSF leak and the continued lumbar CSF drainage post-operatively decreased the volume of CSF, thereby decreasing CSF pressure. This phenomenon may lead to increased perfusion pressure and passive edema [18]. Increased perfusion pressure could potentially lead to over-distension of cerebral veins and arterioles causing hydrostatic extravasation of fluid [17]. Reduced CSF volume leading to increased perfusion has been reported following repeated lumbar punctures or 
lumbar drainage thereby leading to the development of PRES $[9,10]$. Pressure-volume relationships have been extensively studied and have fit most closely with a parabolic regression model [19-21]. The application of the MonroeKellie doctrine implies that a decrease in CSF volume is met with a compensation in the occupation of the space in the cranium. Since the brain cannot significantly expand, this leads to a resultant hyperemia. This has been correlated with post-lumbar puncture headaches and the effectiveness of caffeine in treating them [22-25]. Inflammation has been extensively shown to disrupt the bloodbrain barrier [26]. The immune background possibly associated with PRES could lead to the increased hydrostatic extravasation when paired with hyperemia secondary to CSF volume depletion [27, 28]. In our patient, CSF volume was decreased due to the intraoperative CSF leak and the lumbar drainage. The patient had mounted a background inflammatory response to the surgical intervention three days prior to the inciting event. Following the removal of the drain, the patient possibly experienced an acute additional decrease in CSF volume and pressure. In the setting of increased inflammation post-operatively, that could have possibly incited the extravasation of fluid and the development of symptoms. The absence of continued CSF leak and the restoration of the normal distribution of the intracranial volume following removal could explain the rapid resolution of the symptoms. The occurrence of PRES is very rare in post-operative patients, which indicates that other underlying pathways may be involved. The limitation of this study is the fact that this phenomenon occurred in a single patient only.

PRES is a potential consideration in post-operative patients with CSF leak with sudden neurological changes, specifically deficits in vision or seizures. The mechanism of PRES remains controversial and further investigations should be conducted whenever it does occur to advance our understanding of its etiology.

\section{Abbreviations}

CNS: Central nervous system; CPP: Cerebral perfusion pressure; CSF: Cerebrospinal fluid; CT: Computed Tomography; FLAIR: Fluid-attenuated Inversion recovery; ICP: Intracranial pressure; MAP: Mean arterial pressure; MRI: Magnetic Resonance Imaging; PRES: Posterior Reversible Encephalopathy Syndrome

\section{Acknowledgements}

Not applicable.

\section{Authors' contributions}

$\mathrm{BO}$ and NK analyzed and interpreted the patient data. BO, NK, SA and AS contributed to the writing of the manuscript. BW supervised and critically revised the manuscript. All authors read and approved the final manuscript.

\section{Funding}

No funding was available for the conduct of this study.

\section{Availability of data and materials}

The datasets used and/or analyzed during the current study are available from the corresponding author on reasonable request.

\section{Ethics approval and consent to participate}

The University of Louisville Institutional Review Board approved this research study and the patient has consented to the submission of this case report for publication.

\section{Consent for publication}

Written informed consent was obtained from the patient to publish the information relating to his course in the hospital.

\section{Competing interests}

The authors declare that they have no competing interests.

Received: 18 June 2019 Accepted: 21 August 2019

Published online: 30 August 2019

\section{References}

1. Hinchey J, Chaves C, Appignani B, Breen J, Pao L, Wang A, et al. A reversible posterior leukoencephalopathy syndrome. N Engl J Med. 1996;334(8):494-500.

2. Bartynski WS. Posterior reversible encephalopathy syndrome, part 1: fundamental imaging and clinical features. AJNR Am J Neuroradiol. 2008:29(6):1036-42.

3. Ducros A, Boukobza M, Porcher R, Sarov M, Valade D, Bousser MG. The clinical and radiological spectrum of reversible cerebral vasoconstriction syndrome. A prospective series of 67 patients. Brain. 2007;130(Pt 12):3091-101.

4. Bartynski WS, Zeigler Z, Spearman MP, Lin L, Shadduck RK, Lister J. Etiology of cortical and white matter lesions in cyclosporin-a and FK-506 neurotoxicity. AJNR Am J Neuroradiol. 2001;22(10):1901-14.

5. McKinney AM, Short J, Truwit CL, McKinney ZJ, Kozak OS, SantaCruz KS, et al. Posterior reversible encephalopathy syndrome: incidence of atypical regions of involvement and imaging findings. AJR Am J Roentgenol. 2007;189(4):904-12.

6. Keyserling HF, Provenzale JM. Atypical imaging findings in a near-fatal case of posterior reversible encephalopathy syndrome in a child. AJR Am J Roentgenol. 2007;188(1):219-21.

7. Doherty H, Hameed S, Ahmed I, Russell IF. Post-dural puncture headache and posterior reversible encephalopathy syndrome: a misdiagnosis or copresentation? Int J Obstet Anesth. 2014;23(3):279-82.

8. Grelat M, Debaux JB, Sautreaux JL. Posterior reversible encephalopathy syndrome after depletive lumbar puncture: a case report. J Med Case Rep. 2014;8:261.

9. Ho CM, Chan KH. Posterior reversible encephalopathy syndrome with vasospasm in a postpartum woman after postdural puncture headache following spinal anesthesia. Anesth Analg. 2007;105(3):770-2

10. Torrillo TM, Bronster DJ, Beilin Y. Delayed diagnosis of posterior reversible encephalopathy syndrome (PRES) in a parturient with preeclampsia after inadvertent dural puncture. Int J Obstet Anesth. 2007;16(2):171-4.

11. Schwartz RB, Bravo SM, Klufas RA, Hsu L, Barnes PD, Robson CD, et al. Cyclosporine neurotoxicity and its relationship to hypertensive encephalopathy: CT and MR findings in 16 cases. AJR Am J Roentgenol. 1995;165(3):627-31.

12. Schwartz RB, Jones KM, Kalina P, Bajakian RL, Mantello MT, Garada B, et al. Hypertensive encephalopathy: findings on CT, MR imaging, and SPECT imaging in 14 cases. AJR Am J Roentgenol. 1992;159(2):379-83.

13. Trommer BL, Homer D, Mikhael MA. Cerebral vasospasm and eclampsia. Stroke. 1988;19(3):326-9.

14. Marra A, Vargas M, Striano P, Del Guercio L, Buonanno P, Servillo G. Posterior reversible encephalopathy syndrome: the endothelial hypotheses. Med Hypotheses. 2014:82(5):619-22.

15. Bartynski WS. Posterior reversible encephalopathy syndrome, part 2 controversies surrounding pathophysiology of vasogenic edema. AJNR Am J Neuroradiol. 2008;29(6):1043-9.

16. Avecillas-Chasín JM, Gómez G, Jorquera M, Alvarado LR, Barcia JA. Delayed posterior reversible encephalopathy syndrome (PRES) after posterior fossa surgery. Acta Neurochir. 2013;155(6):1045-7.

17. Santillan A, Aamodt W, Bhavaraju-Sanka R. Pearls and oy-sters: spontaneous intracranial hypotension and posterior reversible encephalopathy syndrome. Neurology. 2016;86(6):e55-e7.

18. Shields LBE, Johnson JR, Shields CB. Posterior reversible encephalopathy syndrome following a thoracic discectomy-induced dural leak: case report. J Neurosurg Spine. 2016;25(5):586-90. 
19. Lai H-Y, Lee C-H, Lee C-Y. The intracranial volume pressure response in increased intracranial pressure patients: clinical significance of the volume pressure indicator. PLoS One. 2016;11(10):e0164263.

20. Lai H-Y, Lee $\mathrm{C}-\mathrm{Y}$, Hsu H-H, Lee S-T. The intracranial volume pressure response in increased intracranial pressure patients: part 1. Calculation of the volume pressure indicator. Acta Neurochir. 2012;154(12):2271-5.

21. Marmarou A, Shulman K, Rosende RM. A nonlinear analysis of the cerebrospinal fluid system and intracranial pressure dynamics. J Neurosurg 1978;48(3):332-44.

22. Mokri B. The Monro-Kellie hypothesis: applications in CSF volume depletion. Neurology. 2001;56(12):1746-8

23. Mokri B. Spontaneous low pressure, low CSF volume headaches: spontaneous CSF leaks. Headache. 2013;53(7):1034-53.

24. Fishman RA, Dillon WP. Dural enhancement and cerebral displacement secondary to intracranial hypotension. Neurology. 1993:43(3 Pt 1):609-11.

25. Mokri B. Cerebrospinal fluid volume depletion and its emerging clinical/ imaging syndromes. Neurosurg Focus. 2000;9(1):e6.

26. Varatharaj A, Galea I. The blood-brain barrier in systemic inflammation. Brain Behav Immun. 2017;60:1-12.

27. Lee MJ, Cha J, Choi HA, Woo SY, Kim S, Wang SJ, et al. Blood-brain barrier breakdown in reversible cerebral vasoconstriction syndrome: implications for pathophysiology and diagnosis. Ann Neurol. 2017;81(3):454-66.

28. Porcello Marrone LC, Gadonski G, de Oliveira Laguna G, Poli-de-Figueiredo CE, Pinheiro da Costa BE, Lopes MFT, et al. Blood-brain barrier breakdown in reduced uterine perfusion pressure: a possible model of posterior reversible encephalopathy syndrome. J Stroke Cerebrovasc Dis. 2014;23(8):2075-9.

\section{Publisher's Note}

Springer Nature remains neutral with regard to jurisdictional claims in published maps and institutional affiliations.

Ready to submit your research? Choose BMC and benefit from:

- fast, convenient online submission

- thorough peer review by experienced researchers in your field

- rapid publication on acceptance

- support for research data, including large and complex data types

- gold Open Access which fosters wider collaboration and increased citations

- maximum visibility for your research: over $100 \mathrm{M}$ website views per year

At BMC, research is always in progress.

Learn more biomedcentral.com/submissions 